Prive;Volume 3, Nomor 2, September 2020 http://ejurnal.unim.ac.id/index.php/prive

Online ISSN 2615-7314

Printed ISSN $\underline{2615-7306}$

\title{
Analisa Dampak Revitalisasi Pasar Tradisional Terhadap Pendapatan Pedagang Pasar \\ (Studi pada Pasar Tradisional Desa Bulubrangsi Kec. Laren Kabupaten Lamongan)
}

\author{
Hartono ${ }^{1}$ \\ M.Adik Rudiyanto ${ }^{2}$ \\ Fachrudy Asj'ari ${ }^{3}$ \\ 1,2 Universitas Islam majapahit \\ ${ }^{3}$ Universitas PGRI Adi Buana Surabaya \\ hartono.eka@gmail.com
}

\begin{abstract}
This study aims to determine the impact of Traditional Market Revitalization on marked trade Revenues (stud at the Traditional Market in Bulubrangsi Village, Laren District, Regency lamongan. The independent variabel sudied was Market Revitalization impact (X). With the dependent variable being Merchant income $(Y)$ at the Traditional Market of the Bulubangsi Village. The population in this study is that all trades of the Bulubrangsi Traditional Market who are regularly selling on the market evry day. The sampling technikue used in this study is Jenu Sampling technique with a total sample of 98 resondents. Based on the results of testing through partial T test Revitalization variable has a significant effect on the income of traditional market trades in the village of Bulubrangsi $t$ count $=23,159>t$ table $=0,254$ with a signivicant value $0,000<0,05$ From these result it can be concluded that Ho is rejected while Ha is acceoted. This shows that the Revitalization carried out in the Bulubrangsi village Tradistional Market is a positive effect on merchant income.
\end{abstract}

Keywords: Market Revitalization, Merchant Revenue

Abstrak

Penelitian ini bertujuan untuk mengetahui Dampak Revitalisasi pasar Tradisional terhadap Pendapatan Pedagang Pasar (Study pada Pasar Tradisional Desa Bulubrangsi Kec. Laren Kabupaten Lamongan). Variabel independen yang diteliti yaitu Dampak Revitalisasi Pasar (X), dengan variabel dependen yaitu Pendapatan Pedagang (Y) pada Pasar Tradisional Desa Bulubrangsi. Populasi yang terdapat padapenelitian kali ini yaitu seluruh pedagang Pasar Tradisional Desa Bulubrangsi yang secara tetap berjualan di pasar setiap hari.Teknik pengambilan sampel yang digunakan pada penelitian kali ini adalah teknik Sampel Jenu dengan jumlah sampel sebanyak 98 responden. Berdasarkan hasil pengujian melalui uji t secara parsial variabel Revitalisasi memiliki pengaruh signifikan terhadap Pendapatan pedagang Pasar tradisional desa Bulubrangsi $t_{\text {hitung }}=23,159>t_{\text {tabel }}=0,254$ dengan nilai signifikan 0,000 < 0,05.Dari hasil tersebut dapat disimpulkan bahwa $H_{O}$ ditolak sedangkan $H_{a}$ diterima, Hasil penelitian ini menunjukkan bahwa Revitalisasi yang dilakukan pada Pasar Tradisional desa Bulubrangsi adalah berpengaruh positif terhadap Pendapatan pedagang

Kata Kunci: Revitalisasi Pasar, Pendapatan Pedagang 


\section{A. PENDAHULUAN}

Jual beli adalah satu kegiatan yang sama tuanya dengan umur manusia di bumi ini. Kegitan jual beli ini lah yang menjadikan terbentuknya pasar. Di dalam pasar penjual dan pembeli saling berkumpul. Tempat mereka berkumpul biasanya tidak terbuat dari bangunan permanen. Mereka kemudian salin menyepakati harga maka berpindahlah barang dari penjual pada pembeli.

Dalam bahasa latin, pasar dapat ditelusuri melalui akar kata dari kata "mercatus", yang bermakna berdagang atau tempat berdagang. Terdapat tiga makna yang berbeda didalam pengertian tersebut: pasar dalam arti secara fisik, pasar sebagai tempat mengumpulkan dan pasar sebagai hak atau ketentuan yang legal tentang suatu pertemuan pada suatu market place.

Seiring dengan waktu proses jual beli berlangsung tanpa harus bertatap muka antara penjual dan pembeli. Seperti hal nya pembeli memilih brangnya lewat perusahaan perusahaan $E$ Commerce dan membayarpun cukup dengan menggesekkan kartu kredit atau debet. Oleh sebab itu, lahirlah istilah pasar modern dan pasar tradisional yang berfungsi sama dalam pemenuhan kebutuhan manusia sehari hari. Pasar tradisional sudah mulai dikenal sejak jaman kerajaan kutai karta negara, yakni abad ke 5 Masehi. Aktifitas jual beli ini semakin ramai dilakukan seiring dengan masuknya para pelaut dari negeri cina yang juga melakukan aktifitas barter barang. Beberapa relief sejumlah candi dinusantara menceritakan kisah masyarakat zaman kerajaan ketika bertransaksi jual beli meskipun tidak secara mendetail. Perkembangaan selanjutnya digunakanlah mata uang dari negeri cina sebagai legalitas jual beli. Pasar kemudian bukan hanya menjadi tempa jual beli barang atau tempat transaksi pedagang dan pembeli tetapi juga tempaat jual beli alat produksi dan jasa.

Akhir akhir ini kita sering mendengar dari media cetak maupun electronik parapedagang pasar tradisional ramai ramai menolak Renovasi pasar. Mereka berunjuk rasa dan menentang keras rencana renovasi yang dilakukaan oleh pemerintah karena khawatir hal itu akan semakin merugikan para pedagang pasar. Mungkin agak mengherankan karena bukankah pasar tradisional dengan segenap kesannegatifnya perlu direhabilitasi agar lebih menarik, enak dipandang dan nyaman untuk aktifitas jual beli.

Program revitalisasi pasar tradisional ini adalah salah satu program penting di era Presiden Jokowi. Ditargetkan diera Presiden Jokowi akan dalaam 5 tahun akan merevitalisasi 5000 pasar dari Sabang sampai Merauke dan dari Miangas sampai pulau Rote.

\section{B. TELAAH LITERATUR DAN PENGEMBANGAN HIPOTESIS}

\section{Peran Konsep Pasar}

\section{a. Pasar}

Menurut Dr. Sudaryono (2016:37) Secara teoritis pasar menggambarkan semua pembeli dan penjual yang terlibat dalam transaksi aktual atau potensial atas barang atau jasa yang ditawarkan.Pasar juga merupakan lembaga ekonomi dimana para pembeli dan para penjual, baik secara langsung dan tidak langsung dapat melakukan transaksi perdagangan barang atau jasa. Jadi dapat diartikan pasar merupakan tempat bertemunya penjual dan pembeli untuk melakukan transaksi

\section{b. Jenis-jenis Pasar}

Menurut Tri Kunawangsih Pracoyo dan Antyo Pracoyo (2006:17) pasar dibedakan menjadi dua jenis utama yakni:

1. Pasar output (pasar barang/pasar produksi), merupaka penjualan output barang dan jasa.

2. Pasar input (pasar faktor produksi, merupakan tempat penjuala jasa faktor produksi).

Dalam hal ini Sadono Sukirno (2015:40) menjelaskan bahwa pasar sebagai tempat para pembeli dan penjual melakukan interaksi dapat dibedakan dalam dua jenis yaitu:

a) Pasar barang adalah tempat di mana para pembeli dan para penjual dri suatu barang atau jasa melakukan interaksi untuk menentukan jumlah dan harga barang atau jasa yang diperjualbelikan.

b) Pasar faktor adalah tempat dimana pengusaha (pembeli faktor-faktorproduksi) mengadakan interaksi dengan pemilik-pemilik faktor produksiuntuk menentukan harga 
(pendapatan) dan jumlah faktor-faktor produksiyang akan digunakan dalam menghasilkan barang-barang dan jasa-jasayang diminta masyarakat.

\section{Pasar Tradisional}

Menurut Herman Malano (2011:69). Pasar tradisional berdiri karena masyarakat ingin memperoleh berbagai kebutuhan hidup. Pada zaman dahulu karena belum ada uang, masyarakat bertransaksidengan tukar menukar barang yang disebut dengan sistem barter. Para petani, peternak, nelayan dan pekerja lainnya bertransaksi dengan menukarkan hasil produksi masing-masing. Awalnya pertukaran itu terjadi disembaraang tempat, lama ke lamaan masyarakat atas kesepakatan bersama mensetujui tempat untuk melaksanakan barter. Hal itu lah yang mencikal bakali berdirinya pasar-pasar tradisional sehingga dapat berkembang sampai sekarang.

Konsep Revitalisasi Pasar

Pandangan Danisworo (2002:42) revitalisasi adalah upaya untuk memvitalkankembali suatu kawasan atau bagian kota yang dulunya pernah vital atau hidup,akan tetapi kemudian mengalami kemunduran atau degradasi sehingga adanyapembaharuan dalam aspek fisik dan aspek ekonomi. Program revitalisasi pasar tradisional merupakan pelaksanaan dari UndangundangNomor 7 Tahun 2014 tentang Perdagangan, yang dijelaskan pada pasal 13 yang mengamanatkan bahwa Pemerintah bekerja sama dengan Pemerintah Daerah melakukan:

a) pembangunan, pemberdayaan, dan peningkatan kualitas pengelolaan Pasar Rakyat dalam rangka peningkatan daya saing yang dilakukan dalam bentuk.

b) Pembangunan dan atau revitalisasi Pasar Rakyat.

c) Implementasi manajemen pengelolaan yang professional

d) Fasilitas akses penyediaan barang dengan mutu yang baik dan harga yangbersaing; dan

e) Fasilitas akses pembiayaan kepada pedagang Pasar di Pasar Rakyat.Ketentuan lebih lanjut mengenai pembangunan, pemberdayaan dan peningkatankualitas pengelolaan Pasar Rakyat diatur dengan atau berdasarkan PeraturanPresiden

Konsep Pendapatan

Menurut Rudianto (2012:48) Pendapatan merupakan suatu bentuk balas jasa yang diterima suatu pihak atas keikut sertaannya dalam proses produksi barang dan jasa. Dalam arti sempit Pendapatan adalah kenaikan jumlah aset yang disebabkan oleh penjualan produk perusahaan. Selain itu pendapatan juga dapat di definisikan sebagai penghasilan dari usaha pokok perusahaan atau penjualan barang atau jasa diikuti biaya-biaya sehingga diperoleh laba kotor.

Rudianto (2012:48) Pendapatan merupakan suatu bentuk balas jasa yang diterima suatu pihak atas keikut sertaannya dalam proses produksi barang dan jasa. Pendapatan adalah kenaikan jumlah aset yang disebabkan oleh penjualan produk perusahaan.

\section{Kerangka Konseptual}

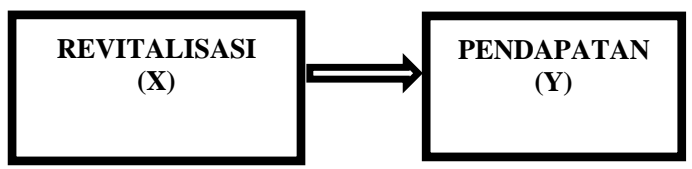

\section{Hipotesis}

Hipotesis merupakan dugaan sementara terhadap rumusan permasalahan. Hipotesis tersebut akan diterima jika mempunyai fakta yang benar dan akan ditolak apabila mempunyai fakta yang salah. Hipotesis ini dimaksudkan untuk memberi arahan bagi analisis penelitian. Maka yang menjadi kesimpulan sementaranya adalah sebagai berikut :

H1 : Revitalisasi Pasar Berdampak Terhadap Penigkatan Pendapatan Pedagang di Desa Bulubrangsi. 


\section{METODE PENELITIAN}

1. Pendekatan Penelitian

Menurut Sugiyono (2016:3), jenis penelitian ini dapat digolongkan penelitian asosiatif. Penelitian asosiatif merupakan penelitian yang bertujuan untuk mengetahui ada dan tidaknya pengaruh atau hubungan antara variabel bebas terhadap variabel terikat dan apabila ada seberapakah eratnya pengaruh atau hubungan serta berarti atau tidaknya pengaruh atau hubungan itu.

Jenis data yang digunakan penelitian ini adalah jenis data kuantitatif. Menurut Sugiyono (2017:7), kuantitatif dinamakan metode tradisional, karena metode ini sudah cukup lama digunakan sehingga sudah mentradisi untuk penelitian. Metode ini disebut sebagai metode positivistik karena berlandaskan pada filsafat positivisme.Metode ini disebut metoe kuantitatif karena data penelitian berupa angka-angka an analisis menggunakan statistik.

2. Tempat Dan Waktu Penelitian

Penelitian bertempat di pasar tradisional desa Bulubrangsi kecamatan Laren, kabupaten Lamongan, provinsi Jawa Timur. Waktu penelitian ini dilaksanakan mulai bulan April sampai dengan bulan Desember 2019

Obyek Penelitian

Objek dari penelitian ini adalah seluruh pedagang pasar tradisional Bulubrangsi Laren, Lamongan.Penelitian ini menggunakan metode penelitian kuantitatif, yang mana untuk pengumpulan data menggunakan data primer dan data sekunder. Data primer diperoleh dari jawaban para pedagang pasar tradisional desa bulubrangsi langsung melalui kusioner yang dibagikan, sedangkan untuk data sekunder akan diperoleh dari data-data yang akan diberikan oleh pengelolah pasar.

Populasi, Sampel Dan Teknik Pengambilan Sampel

Populasi dan sampel

Menurut Sugiyono (2017:80), populasi adalah wilayah generalisasi yang terdiri atas: obyek/subyek yang mempunyai kualitas dan karakteristik tertentu yang ditetapkan oleh peneliti untuk dipelajari dan kemudian ditarik kesimpulannya.Smpel adalah bagian jumlah dan karakteristik yang dimiliki oleh populasi tersebut. Dari keseluruhan populasi yang akan diambil pada pedagang pasar tradisional desa Bulubrangsi kecamatan Laren, Lamonganmaka dalam penelitian ini semua subjek penelitian (populasi) digunakan sebagai sampel yaitu seluruh pedagang pasar tradisional desa Bulubrangsi kecamatan Laren, Lamongan karyawan yang berjumlah 98 Pedagang.

3. Teknik Pengambilan Sampel

Menurut Sugiyono (2017:81), teknik sampling merupakan teknik pengambilan sampel. Teknik pengambilan sampel pada penelitian adalah teknik penarikan sampel jenuh (sensus) dengan mengambil seluruh populasi sebagai resonden.Dimana sampel dalam penelitian ini adalah seluruh Pedagang Pasar Tradisional desa Bulubrangsi kecamatan Laren, Lamongan yang berjumlah 98 pedagang.

4. Variabel Penelitian

Menurut Sugiyono (2017:38) variabel penelitian di definisikan sebagai atribut seseorang atau obyek yang mempunyai "variasi" antara satu orang dengan yang lain atau satu obyek dengan obyek yang lain (Hatch dan Farhadi, 1981). Variabel juga dapat merupakan atribut dari bidang keilmuan atau kegiatan tertentu. Tinggi, berat badan, sikap, motivasi, kepemimpinan, disiplin kerja merupakan atribut-atribut dari setiap orang.

1. Variabel Independen (variabel bebas) merupakan variabel yang mempengaruhi atau menjadi sebab perubahannya atau timbulnya variabel dependen (terikat).

2. Variabel Dependen (Variabel terikat) merupakan variabel yang dipengaruhi atau yang menjadi akibat, karena adanya variabel bebas. Variabel yang digunakan dalam penelitian kali ini adalah :

1. Variabel bebas (independent variabel), Revitalisasi Pasar(X1)

2. Variabel terikat (dependent variable), Pendapatan Pedagang (Y). 
5. Teknik Pengumpulan Data

Untuk memperoleh data yang lengkap dan teliti dalam penelitian, teknik pengumpulan data yang digunakan adalah:

a. Daftar pertanyaan (quesioner)

Menurut Sugiyono (2017:142) kusioner merupakan teknik pengumpulan data yang dilakukan dengan cara memberi seperangkat pertanyaan atau pernyataan tertulis kepada responden untuk dijawabnya. Beberapa prinsip dalam penulisan angket sebagai teknik pengumpulan data yaitu: prinsip penulisan, pengukuran dan penampilan fisik.

b. Observasi

Menurut Sugiyono (2017:145), mengemukakan bahwa, observasi merupakan suatu proses yang kompleks, suatu proses yang tersusun dari berbagai proses biologis dan psikologis. Dua diantaranya yang terpenting adalah proses-proses pengamatan dan ingatan.

6. Metode Analisis Data

1. Uji Validitas

2. Uji Reliabilitas

3. Uji Asumsi Klasik
a. Uji moltokoloneritas
b. Uji Heteroskedastisitas
c. Uji Normalitas
d. Uji Autokolerasi

4. Uji Hipotesis

a. Uji T

\section{HASIL DAN PEMBAHASAN}

\section{Gambaran Umum Pasar dan Desa Bulubrangsi}

Desa Bulubrangsi merupakan salah satu desa yang berada di Kecamatan Laren Kabupaten Lamongan, tepatnya berada di sebelah utara dari pusat Kabupaten Lamongan. untuk menuju desa ini dari pusat Kabupaten Lamonagn sendiri lumayan jauh yakni berkisar $20 \mathrm{~km}$, sedangkna jarak Desa Bulubrangsi dengan Kecamatan Laren sendiri lumayan dekat yakni berkisar $9 \mathrm{~km}$. Jalan akses ke Desa Bulubrangsi sendiri tidak begitu sulit, hal ini dikarenakan jalan sudah beraspal dan tertata dengan baik. Tidak heran apabila setiap hari banyak kendaraan hilir mudik yang melewati Desa Bulubrangsi karena menjadi jalan alternatif menuju pusat Kota Lamongan. Desa Bulubrangsi memiliki wilayah cukup luas bila dibandingkan dengan desa-desa yang ada di Kecamatan Laren yakni terdiri dari 5 RW dan 5 RT dengan total wilayah seluas 392,19 km.

Desa Bulubrangsi juga memiliki batas wilayah sebagai berikut:

$>$ Sebelah Utara berbatasan dengan Desa Solokuro

$>$ Sebelah Selatan berbatasan dengan Desa Karang Wungu

$>$ Sebelah Barat berbatasan dengan Desa Godog

$>$ Sebelah Timur berbatasan dengan Desa Brangsi

Sejarah Pasar Tradisional Desa Bulubrangsi

Pasar desa Bulubrangsi merupakan salah satu pasar yang ada di Kec. Laren Lamongan tepatnya di desa Bulubrangsi jalan. Pasar desa Bulubrangsi merupakan satu satu satunya pasar yang buka setiap pagi diwilayah Kec. Laren.. Letaknya yang strategis membuat peluang bagi para pedagang yang ada di Pasar tersebut, karena banyak nya masyarakat yang datang dari berbagai desa tetangga maupun kecamatan berbelanja ke Pasar desa Bulubrangsi. Pasar tradisional merupakan Pasar rakyat yang tidak dapat dipungkiri lagi masyarakat akan selalu berbelanja ke Pasar

Tradisional karena segala kebutuhan ada di Pasar dan tidak hanya harga yang lebih murah dan dapat melakukan tawar menawar. Begitupula dengan Pasar desa Bulubrangsi.

2. Karateristik Responden

Pada ini disebarkan kepada seluruh pedagang pasar tradisional desa Bulubrangsi yang berjumlah 98 pedagang. Dari data yang diperoleh yang telah klarifikasikan mengenai data responden yang telah diolah menggunakan SPSS versi 22 sebagai berikut: 
1. Karateristik Responden Berdasarkan Jenis Kelamin

Tabel 1

Karakteristik Responden Berdasarkan Jenis Kelamin jenis kelamin

Jenis Kelamin

\begin{tabular}{|ll|l|l|l|l|}
\hline & \multicolumn{2}{|l|}{$\begin{array}{l}\text { Frequenc } \\
\text { y }\end{array}$} & Percent & Valid & \multicolumn{2}{l|}{ Pumulative } \\
& & Percent & Percent \\
\hline Valid & Laki-Laki & 25 & 8,6 & 8,6 & 8,6 \\
& Perempuan & 73 & 91,4 & 91,4 & 100,0 \\
& Total & 98 & 100,0 & 100,0 & \\
\hline
\end{tabular}

Berdasarkan table 1 diatas menunjukkan bahwa responden penelitian yaitu pedagang pasar tradisional desa Bulubrangsi mayoritas perempuan 91,4\% sedangkan laki-laki yaitu 8,6\%. Data ini menggambarkan bahwa pada pasar tradisional desa Bulubrangsi lebih banyak pedagang berjenis kelamin Perempuan.

2. Karakteristik responden berdasarkan Usia

\section{Tabel 2}

Karakteristik Responden Berdasarkan Jenis Usia

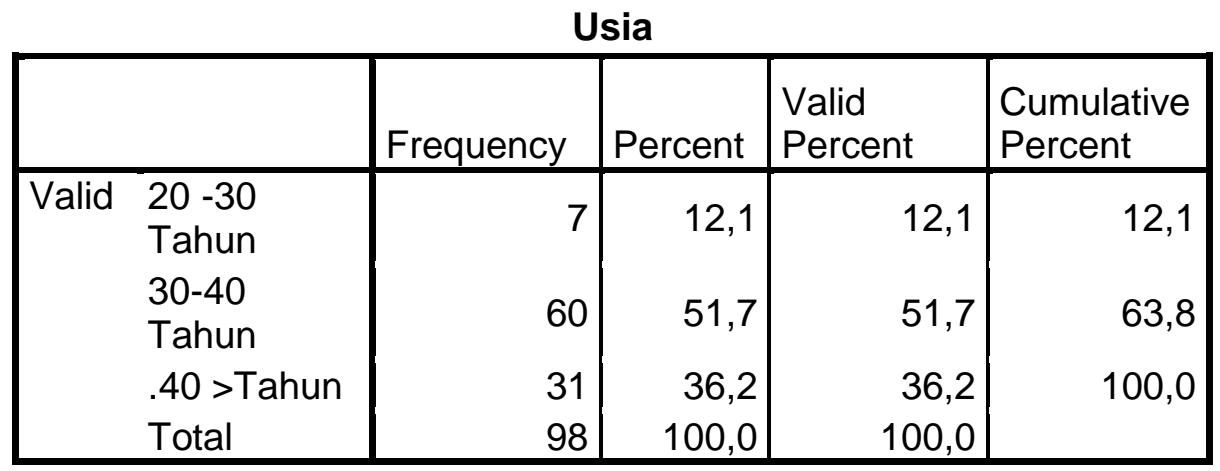

Berdasarkan Tabel 2 dapat diketahui bahwa usia responden dari penelitian ini adalah 20-30 tahun yaitu sebanyak 7 responden atau dalam presentasi sebanyak $12,1 \%$.Usia 3040 tahun sebanyak 60 orang atau dalam presentase $51,7 \%$. Sedangkan usia diatas $40>$ tahun sebanyak 31 orang atau dalam prosentase $36,2 \%$. Hal ini menunjukkan bahwasanya pedagang di pasar tradisional desa Bulubrangsi berumur beragam dan didominasi usia 3040 tahun sebanyak 60 edagang.

3. Karakterisi Responden Berdasarkan Jenis Dagangan

Tabel 3

Karakteristik Responden Berdasrkan Jenis Dagangan

\begin{tabular}{|c|c|c|c|c|c|}
\hline & & Frequency & Percent & $\begin{array}{l}\text { Valid } \\
\text { Percent }\end{array}$ & $\begin{array}{l}\text { Cumulative } \\
\text { Percent }\end{array}$ \\
\hline \multirow[t]{3}{*}{ Valid } & Pangan & 64 & 75,9 & 75,9 & 75,9 \\
\hline & Non pangan & 34 & 24,1 & 24,1 & 100,0 \\
\hline & Total & 98 & 100,0 & 100,0 & \\
\hline
\end{tabular}


Berdasarkan Tabel 3 dapat diketahui bahwa jenis dagangan para pedagang pasar tradisional desa Bulubrangsi 64 pedagang menjajakan dagangan pangan dengan presentase 75,9\% dan 34 pedagang menjajakan dagangan non pangan dengan presentase $24,1 \%$. Hal ini menunjukkan pedagang yang menjajakan dagangan pangan lebih banyak dibandingkan dengan yang menjajakan dagangan non pangan.

4. Deskripsi Variabel Penelitian

Analisa Dampak Revitalisasi Terhadap Pendapatan Pedagang Pasartradisional desa Bulubrangsi akan dilihat dalam indikator variabel masing masing. Berikut adalah data kuisoner yang telah diisi oleh 98 pedagang pasar.

\section{Revitalisasi (X)}

Adapun jawaban responden mengenai Revitalisasi adalah sebagai berikut:

Tabel 4

Jawaban Responden Terhadap Variabel Revitalisasi

\begin{tabular}{|l|l|l|l|l|l|l|}
\hline No. & Pernyataan & SS & S & N & TS & STS \\
\hline $\mathbf{1 .}$ & $\begin{array}{l}\text { Pengamen dan pengemis dipasar } \\
\text { tradisional desa Bulubrangsi berkurang } \\
\text { setelah program Revitalisasi }\end{array}$ & $\mathbf{5 2}$ & $\mathbf{1 9}$ & $\mathbf{7}$ & $\mathbf{1 7}$ & $\mathbf{3}$ \\
\hline $\mathbf{2 .}$ & $\begin{array}{l}\text { Setelah Revitalisasi pedagang pasar lebih } \\
\text { leluasa melakukan kegiatan jual beli }\end{array}$ & $\mathbf{5 7}$ & $\mathbf{1 4}$ & $\mathbf{1 2}$ & $\mathbf{1 4}$ & $\mathbf{1}$ \\
\hline $\mathbf{3 .}$ & $\begin{array}{l}\text { Pedagang pasar tidak merasa keberatan } \\
\text { terhadap tambahan biaya sebelum dan } \\
\text { sesudah Revitalisasi }\end{array}$ & $\mathbf{5 7}$ & $\mathbf{1 6}$ & $\mathbf{1 6}$ & $\mathbf{9}$ & - \\
\hline
\end{tabular}

Pada tabel 4 diatas dapat dilihat dari 98 responden yang diteliti terlihat diantara seluruh variabel Revitalisasi yang diteliti memiliki kriteria responden lebih besar berada pada pernyataan setuju. Berdasrkan pernyataan pada kuisoner menunjukan bahwa jawaban pedagang terhadap variabel revitalisasi umumnya baik.

Pendapatan (Y)

Adapun jawaban responden mengenai variabel Pendapatan adalah sebagai berikut:

Tabel 5

Jawaban Responden Terhadap Variabel Pendapatan

\begin{tabular}{|l|l|l|l|l|l|c|}
\hline No. & Pernyataan & SS & S & N & TS & STS \\
\hline $\mathbf{1 .}$ & $\begin{array}{l}\text { Pendapatan pedagang meningkat } \\
\text { setelah Revitalisasi }\end{array}$ & $\mathbf{5 4}$ & $\mathbf{1 7}$ & $\mathbf{1 5}$ & $\mathbf{1 0}$ & $\mathbf{2}$ \\
\hline 2. & $\begin{array}{l}\text { Setelah Program Revitalisasi } \\
\text { Pedagang Pasar Mengeluarkan } \\
\text { Modal Yang Sama Dengan Sebelum } \\
\text { Revitalisasi dengan pendapatan yang } \\
\text { lebih besar. }\end{array}$ & $\mathbf{1 5}$ & $\mathbf{1 3}$ & $\mathbf{1 4}$ & - & \\
\hline
\end{tabular}




\begin{tabular}{|l|l|l|l|l|l|l|}
\hline 3. & $\begin{array}{l}\text { Setelah Revitalisasi pendapatan } \\
\text { pedagang selalu lebih besar dari pada } \\
\text { pengeluaran pedagang. }\end{array}$ & $\mathbf{5 5}$ & $\mathbf{1 6}$ & $\mathbf{2 0}$ & $\mathbf{7}$ & - \\
\hline
\end{tabular}

Pada tabel 5 diatas dapat dilihat dari 98 responden yang diteliti terlihat diantara seluruh variabel pendapatan yang diteliti memiliki kriteria responden lebih besar berada pada pernyataan setuju.Berdasarkan pernyataan pada kuisoner menunjukan bahwa jawaban konsumen terhadap variabel kualitas pendapatan umumnya baik.

Uji Validitas dan Uji Reliabilitas

a. Uji Validitas

Tabel 6

Hasil Uji Validitas Menggunakan SPSS

Correlations

\begin{tabular}{|c|c|c|c|c|c|}
\hline & & $\mathrm{X} 1.1$ & $\mathrm{X} 1.2$ & $\mathrm{X} 1.3$ & Revitalisasi \\
\hline \multirow[t]{3}{*}{$\mathrm{X} 1.1$} & $\begin{array}{l}\text { Pearson } \\
\text { Correlation }\end{array}$ & 1 & & & 949* \\
\hline & Sig. (2-tailed) & & ,000 &, 000 & ,000 \\
\hline & $\mathrm{N}$ & 98 & 98 & 98 & 98 \\
\hline \multirow[t]{3}{*}{$\mathrm{X} 1.2$} & $\begin{array}{l}\text { Pearson } \\
\text { Correlation }\end{array}$ & $805^{* *}$ & 1 & ,680** & (909** \\
\hline & Sig. (2-tailed) &, 000 & & ,000 &, 000 \\
\hline & $\mathrm{N}$ & 98 & 98 & 98 & 98 \\
\hline \multirow[t]{3}{*}{$\mathrm{X} 1.3$} & $\begin{array}{l}\text { Pearson } \\
\text { Correlation }\end{array}$ & ,793* & ,680* & 1 & ,890" \\
\hline & Sig. (2-tailed) &, 000 &, 000 & & ,000 \\
\hline & $\mathrm{N}$ & 98 & 98 & 98 & 98 \\
\hline \multirow[t]{3}{*}{$\begin{array}{l}\text { Revitalisas } \\
\mathrm{i}\end{array}$} & $\begin{array}{l}\text { Pearson } \\
\text { Correlation }\end{array}$ & $949^{* *}$ & ,909** & ,890* & 1 \\
\hline & Sig. (2-tailed) & , 000 & , 000 & , 000 & \\
\hline & $\mathrm{N}$ & 98 & 98 & 98 & 98 \\
\hline
\end{tabular}

Dari output di atas menjelaskan bahwa $\mathrm{N}=98$ pada signifikansi 5\% diperoleh 0,254 ( $\mathrm{r}$ tabel), butir pertanyaan dikatan valid jika $r$ hitung $>r$ tabel atau nilai $p<0,05$

Tabel 7

Hasil Uji Validitas Menggunakan SPSS

\section{Correlations}

\begin{tabular}{|rl|r|r|r|r|}
\hline & Y.1 & Y.2 & \multicolumn{1}{|c|}{ Y.3 } & Pendapatan \\
\hline Y.1 & Pearson & 1 &, $718^{* *}$ &, $695^{* *}$ &, $888^{* *}$ \\
& Correlation & &, 000 &, 000 &, 000 \\
& Sig. (2-tailed) & 98 & 98 & 98 & 98 \\
\hline N &, $718^{* *}$ & 1 &, $829^{* *}$ &, $932^{* *}$ \\
& Pearson &, 000 & &, 000 &, 000 \\
& Correlation & 98 & 98 & 98 & 98 \\
\hline
\end{tabular}




\begin{tabular}{|ll|r|r|r|r|} 
Y.3 & Pearson &, $695^{* *}$ &, $829^{* *}$ & 1 &, $915^{* *}$ \\
& Correlation &, 000 &, 000 & &, 000 \\
& Sig. (2-tailed) & 98 & 98 & 98 & 98 \\
\hline $\mathrm{N}$ &, $888^{* *}$ &, $932^{* *}$ &, $915^{* *}$ & 1 \\
\hline Pendapata & Pearson &, 000 &, 000 &, 000 & \\
$\mathrm{n}$ & Correlation & 98 & 98 & 98 & 98 \\
& Sig. (2-tailed) & & & \\
& $\mathrm{N}$ & & & \\
\end{tabular}

Dari output di atas menjelaskan bahwa $\mathrm{N}=98$ pada signifikansi $5 \%$ diperoleh 0,254 ( $\mathrm{r}$ tabel), butir pertanyaan dikatan valid jika $\mathrm{r}$ hitung $>\mathrm{r}$ tabel atau nilai $\mathrm{p}<0,05$

b. Uji Reliabilitas

Uji reliabilitas digunakan untuk melihat apakah alat yang digunakan (kusioner) menunjukkan konsistensi dalam mengukur gejala yang sama. Pengujian dilakukan dengan program SPSS. Butir pertanyaan yang sudah dinyatakan valid dalam uji validitas, ditentukan realibilitasnya dengan kriteria sebagai berikut: jika nilai (Cronbach's Alpha) diatas 0,6 ini berarti kusioner tersebut telah reliabel dan dapat disebarkan kepada responden untuk dijadikan sebagai instrumen penelitian.

Adapun hasil uji reliabilitas yang diperoleh dari 98 pedagang pada pasar tradisional desa Bulubrangsi.

\begin{tabular}{|c|c|}
\hline $\begin{array}{r}\text { Hasil } \\
\text { Reliability Sta }\end{array}$ & $\begin{array}{l}\text { Tabel } 8 \\
\text { Uji Reliabilit } \\
\text { tistics }\end{array}$ \\
\hline $\begin{array}{l}\text { Cronbach's } \\
\text { Alpha }\end{array}$ & $\mathrm{N}$ of Items \\
\hline ,903 & 3 \\
\hline
\end{tabular}

Berdasarkan tabel 8 hasil uji reliabilitas dapat diketahui bahwa nilai cronbach's Alpha 0,903> dari 0,60 seluruh variabel yang diujikan dinyatakan reliabel.

Tabel 9

\section{Hasil Uji Reliabilitas}

Reliability Statistics

\begin{tabular}{|r|r|}
\hline $\begin{array}{l}\text { Cronbach's } \\
\text { Alpha }\end{array}$ & N of Items \\
\hline, 896 & 3 \\
\hline
\end{tabular}

Berdasarkan tabel 9 hasil uji reliabilitas dapat diketahui bahwa nilai cronbach's Alpha 0,896> dari 0,60 seluruh variabel yang diujikan dinyatakan reliabel.

Uji Asumsi Klasik

a. Uji Autokorelasi

Uji Autokorelasi digunakan untuk mengetahui ada atau tidaknya penyimpangan asumsi klasik aoutokolerasi yaitu korelasi yang terjadi antara residual pada satu pengamatan dengan pengamatan lain pada model regresi. 
Tabel 10

Hasil Uji Autokorelasi

Model Summary

\begin{tabular}{|c|c|c|c|c|c|c|c|}
\hline \multirow[b]{2}{*}{ Model } & \multirow[b]{2}{*}{$\mathrm{R}$} & \multirow[b]{2}{*}{$\begin{array}{l}\mathrm{R} \\
\text { Square }\end{array}$} & \multirow[b]{2}{*}{$\begin{array}{l}\text { Adjusted R } \\
\text { Square }\end{array}$} & \multirow[b]{2}{*}{$\begin{array}{l}\text { Std. Error of } \\
\text { the Estimate }\end{array}$} & \multicolumn{3}{|c|}{ Change Statistics } \\
\hline & & & & & $\begin{array}{l}\text { R Square } \\
\text { Change }\end{array}$ & $\begin{array}{l}\text { F } \\
\text { Change }\end{array}$ & $\begin{array}{l}\mathrm{df} \\
1\end{array}$ \\
\hline 1 &, $952^{a}$ & ,905 & ,904 & ,928 &, 905 & 536,337 & 1 \\
\hline
\end{tabular}

\begin{tabular}{|r|r|r|}
\hline \multicolumn{2}{|l|}{ Change Statistics } & Durbin-Watson \\
\hline df2 & Sig. F Change & \\
\hline 96 &, 000 & 1,770 \\
\hline
\end{tabular}

Dapat dilihat dalam tabel 10 Durbin-Watson dalam penelitian ini adalah 1,770, sedangkan $\mathrm{dL}=1,5052$. Jadi dapat disimpulkan bahwa terjadi autokorelasi karena $\mathrm{dw}<$ $\mathrm{dl}=1,770<1,5052$.

\section{b. Uji Normalitas}

Ghozali (2013:160) uji normalitas bertujuan untuk menguji apakah dalam model regresi, variabel pengganggu atau residual memiliki distribusi normal. Ada dua cara untuk melihat apakah residual distribusi normal atau tidak, yaitu menggunakan analisis grafik dan uji statistik. Cara pengujiannya:

Pada grafik histogram, dikatakan variabel Pendapatan normal atau tidak jika terbentuk lonceng yang melenceng ke kiri atau kekekanan.

Apabila plot dari keduanya terbentuk maka berindikasi bahwa residual menyebar normal. Bila pola titik-titik yang terletak selain diujung-ujung plot masih berbentuk linear, meskipun ujung-ujung plot agak menyimpang dari garis lurus, dapat dikatakan bahwa sebaran data adalah berdistribusi normal. Berkut ini hasil Normal P-Plot of Regression Standardized Residual:

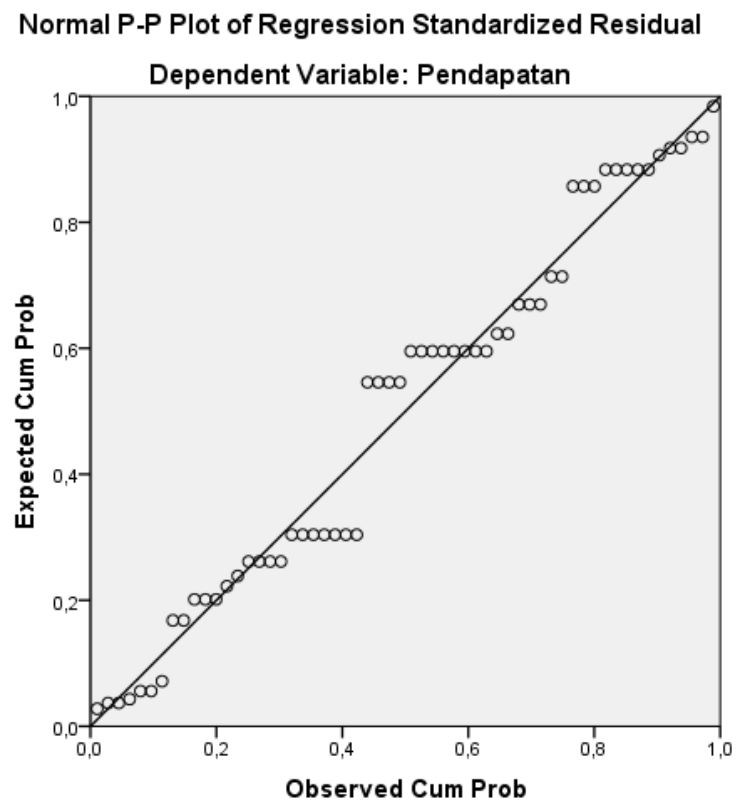

Gambar 1 Pendekatan Grafik Normalitas 
Pada gambar 1 dapat terlihat bahwa titik-titik menyebar disekitar garis diagonal dan mengikuti arah garis diagonal.Hal ini menunjukkan data distribusi normal.

\section{c. Uji Multikolinearitas}

Ghozali (2013:105) uji multikolinearitas bertujuan untuk menguji apakah model regresi ditemukan adanya kolerasi antar variabel bebas (independen).Selain itu, uji digunakan untuk mengetahui kesalahan standar estimasi model dalam penelitian. Apabila nilai VIF $<10$ dan atau nilai Tolerance $>0,10$ maka disimpulkan tidak terdapat masalah multikolinearitas, begitu pula sebaliknya.

Tabel 11

\section{Hasil Uji Multikolinearitas}

\begin{tabular}{|ll|l|l|l|l|}
\hline \multirow{2}{*}{ Model } & \multicolumn{5}{|l|}{ Correlations } \\
\cline { 3 - 6 } & Partial & Part & Tolerance & VIF \\
\hline 1 & & & & & \\
& Revitalisasi &, 952 &, 952 & 1,000 & 1,000 \\
\cline { 2 - 6 } & & & & &
\end{tabular}

Berdasarkan tabel 11 uji multikolineritas di atas dapat dipahami bahwa kedua variabel independen yakni Revitalisasi (X) dan Pendapatan (Y) memiliki memiliki nilai collinnearity statistic VIF 1,000 niai tersebut dapat dipahami dalam batas toleransi yang telah ditentukan, dimana semua variabel mendekati angka 1 dan VIF lebih kecil dari 10. Sehingga demikian dapat disimpulkan bahwa tidak terjadi multikolinieritas dalam Uji hipotesis

variabel independen dalam penelitian.

\section{Uji Parsial (Uji t)}

Uji statistik t dimaksud untuk menguji pengaruh secara parsial.Uji statistik t pada dasarnya menunjukkan seberapa jauh pengaruh satu variabel penjelas secara individual dalam menerangkan variasi variabel terikat. Rumus yang digunakan untuk menguji hipotesis tersebut adalah:

\section{Keterangan:}

$$
t_{\text {hitung }}=\frac{r \sqrt{n-2}}{1-r^{2}}
$$

$\mathrm{n}=$ jumlah data

$\mathrm{r}=$ koefisien korelasi

$\mathrm{t}=$ hasil uji tingkat signifikansi.

1. Kriteria keputusannya adalah:

a) Jika thitung $>\mathrm{t}$ tabel, dan sig $<0,05$ maka Ho ditolak dan Ha diterima.

b) Jika t hitung < t tabel, dan sig $>0,05$ maka Ho diterima dan Ha ditolak.

c) Taraf signifikan $=5 \%$

d) Derajat kebebasan (df) $=\mathrm{n}-3$

Tabel 12

Hasil Pengujian t

\begin{tabular}{|c|c|c|c|c|c|c|}
\hline \multirow{2}{*}{\multicolumn{2}{|c|}{ Model }} & \multicolumn{2}{|c|}{$\begin{array}{l}\text { Unstandardized } \\
\text { Coefficients }\end{array}$} & \multirow{2}{*}{$\begin{array}{l}\text { Standardized } \\
\text { Coefficients } \\
\text { Beta }\end{array}$} & \multirow[b]{2}{*}{$\mathrm{t}$} & \multirow[b]{2}{*}{ Sig. } \\
\hline & & $B$ & Std. Error & & & \\
\hline 1 & (Constant) & 1,409 & ,422 & & 3,336 & ,002 \\
\hline & Revitalisasi & ,883 & ,038 & ,952 & 23,159 &, 000 \\
\hline
\end{tabular}

Dari hasil analisa diatas dapat dijelaskan sebagai berikut: 
a. Nilai t hitung untuk pendapatan (X) adalah 23,159 sedangkan nilai t tabel dengan signifikan 0,000 dan derajat kebebasan (n-k-1) adalah 0,254. Sehingga $t_{\text {hitung }}>t_{\text {tabel. }}$ Jadi dari analisa diatas dapat dijelaskan bahwa $\mathrm{H}_{\mathrm{O}}$ ditolak dan $\mathrm{H}_{\mathrm{a}}$ diterima, artinya secara parsial Revitalisasi (X) memiliki pengaruh yang signifikan terhadap pendapatan pedagang.

\section{E. SIMPULAN DAN SARAN}

Berdasarkan hasil penelitian dan pembahasan tentang analisa dampak revitalisasi pasar tradisional terhadap pendapatan pedagang pasar yang telah diuraikan dapat ditarik kesimpulan sebagai berikut :

1. Hasil pengujian melalui uji t secara persial variabel revitalisasi memiliki pengaruh signifikan terhadap pendapatan pedagang pasar.

2. Hasil pengujian bahwa variabel pendapatan $(\mathrm{X})$ memiliki pengaruh signifikan terhadap pendapatan pedagang pasar tradisional Bulubrangsi.

3. Hasil penelitian regresi koefisien determinasi model summary dapat diketahui bahwa koefisien determinasi ( $\mathrm{R}$ squere ) yang diperoleh dalam penelitian ini sebesar 0,904 atau $90 \%$, sedangkan selisihnya $10 \%$ lainnya dipengaruhi atau dijelaskan oleh variabel yang tidak masuk dalam penelitian ini.

Saran

Setelah peneliti melakukan penelitian ini, maka terdapat saran yang perlu peneliti sampaikan, yakni sebagai berikut :

1. Bagi pengelolah Pasar agar lebih meningkatkan renovasi pada pasar tradisional desa Bulubrangsi sehingga dapat menunjang dan mendorong pendapatan pedagang pasar lebih meningkat lagi.

2. Bagi pemerintah desa Bulubrangsi agar lebih memperhatikan pasr tradisional desa Bulubrangsi sehinggadapat berpengaruh terhadap pedagang khususnya pedagang yang berdomisili di desa Blubrangsi

3. Bagi para peneliti, diharapkan penelitian ini dapat dijadikan sebagai refrensi untuk penelitian selanjutnya dengan variabel yang sama.Penelitian ini belum memberikan hasil yang maksimal dan diharapkan kepada peneliti berikutnya disarankan untuk peneliti lain sehingga permasalahan dan hasilnya juga akan berbeda.

\section{DAFTAR RUJUKAN}

Arissetyanto Nugroho, Aulia Tasman, M. Havidz Aima(2013), Ekonomi Manajerial Dengan Pendekatan Matematis, JakartA, Raja Grafindo Persada,

Danisworo, M. Dan Martokusumo (2002) revitalisasi kawasan kota

Debby Ayoga (2018), Analisis Dampak Revitalisasi Pasar Tradisonal Terhadap Pendapatan Pedagang di Pasar Masaran Cawas

DRS. Subandi, M.M. (2014), Ekonomi Pembangunan, Alfabeta, Bandung

Henry Faizal Noor (2007), Ekonomi Manajerial, Jakarta, Raja Grafindo Persada

Herman Malano (2011) selamatkan pasar tradisional PT. Gran Media, Jakarta

Imam Ghozali (2013), Aplikasi Analisis Multivariate Dengan Program SPSS 22, Universitas Diponegoro Semarang

Mudrajad Kuncoro (2008), Strategi pengembangan Pasar Moderen dan Tradisional, Gra madia Pustaka Utama, Jakarta

Niputu Eka Stutiari dan Sudarsana Arka (2017), Dampak revitalisasi Pasar Tradisional Terhadap Pendapatan Pedagang dan Tata Kelola Pasar di Kabupaten badung

Pratama Raharja (2008), mandala Manurung, Pengantar Ilmu Ekonomi (Mikro Ekonomi danMakroekonomi), Jakarta, LPFE-UI

Rudianto (2012), Pengantar Akuntansi, Adaptasi IFRS, Jakarta, Erlangga

Sadono Sukirno2015, Mikroekonomi Teori Pengantar Edisi Ketiga, 2015 Jakarta: Raja Grafindo Persada, 
Subandi, M.M. (2015), Ekonomi Koperasi, Cetakan ke 5, Alfabeta, Bandung

Sudaryono( 2016) manajemen pemasaran C.V Andi Offset yogyakarta

Sugiyono (2009), Statistika Untuk Penelitian, Cetakan ke 15, Alfabeta, Bandung.

Sugiyono (2016), Metode Penelitian Bisnis, Alfabeta, Bandung

Sugiyono (2017), Metode Penelitian Kuantitatif, Kualitatif, dan $R \& D$, Cetakan ke 26, Alfabeta, Bandung

Tri Kunawangsih Pracoyo \& Antyo Pracoyo2006, Aspek Dasar Ekonomi Mikro,Jakarta,Grasindo,

Veka Verliana (2018), Analisis Pengaruh Revitalisasi Pasar Tradisional Terhadap Pendapatan Pedagang Pasar Dalam Perspektif Ekonomi Islam Pada Pasar Tugu Bandar Lampung, Skripsi, Universitas Islam Negeri Raden Intan Lampung 